\title{
SYNTHESIS AND ANTIVIRAL ACTIVITY OF NEW THIAZOLE, 1,2,4-TRIAZOL AND OXINDOLE DERIVATIVES
}

\author{
${ }^{1}$ Oleg Radul, ${ }^{1}$ Natalia Sucman, ${ }^{1}$ Serghei Pogrebnoi, ${ }^{1}$ Alic Barba, \\ ${ }^{2}$ Athina Geronikaki, ${ }^{1}$ Fliur Macaev* \\ ${ }^{1}$ Institute of Chemistry of the Academy of Sciences of Moldova, \\ Academy str. 3, MD-2028, Chisinau, Moldova \\ Tel +373-22-739-754, Fax +373-22-739-954, E-mail: flmacaev@cc.acad.md \\ ${ }^{2}$ Aristotelian University of Thessaloniki, Thessaloniki 54124, Greece \\ Tel.:+302310997616, Fax: +302310997612 \\ E-mail: geronik@pharm.auth.gr
}

Dedicated to academician Pavel F. Vlad on the occasion of his $75^{\text {th }}$ birthday

\begin{abstract}
The synthesis and antiviral activity evaluation of new derivatives of 2-aminothiazole, 1,2,4-triazole, as well as oxindoles has been realized. The synthesized compounds exhibited different cytotoxicity, in particular, oxindols 4 $, 5,7,8,9,10,11,12,13,58$ as well as thiazole/triazole 73 and 75 turned out to be the most cytotoxic for MT-4 cell lines. The compounds 11, 12, 73, and $\mathbf{7 5}$ are more toxic than reference compound Efavirenz. As far as the antiviral activity is concerned, none of the title compounds turned out active against Reo-1, Sb-1, VSV, RSV, YFV and VV viruses. The results obtained against Bovine Viral Diarrhoea Virus (BVDV) showed that nine compounds (six from oxindol's seria $\mathbf{6}, \mathbf{1 2}, \mathbf{1 3}, \mathbf{5 2}, \mathbf{5 6}, \mathbf{5 8}$ and three $73, \mathbf{7 5}, \mathbf{7 7}$ of triazole homologues) resulted moderate active. Among all of them, the most potent compound was $\mathbf{5 2}$, with $\mathrm{EC}_{50}$ of $6.6 \mu \mathrm{M}$. Studies of effect of synthesized compounds against Coxsakie Virus (CVB-2) revealed that only two compounds, $\mathbf{1 3}$ and $\mathbf{7 3}$ exhibit moderate activity $\left(\mathrm{EC}_{50}>40\right.$ and $>18 \mu \mathrm{M}$, respectively). It should be noticed that eleven compounds, $\mathbf{4}, \mathbf{5}, \mathbf{7}, \mathbf{8}, \mathbf{9}, \mathbf{1 0}, \mathbf{1 1}, \mathbf{1 2}, \mathbf{1 3}, \mathbf{5 8}$, and 75 showed moderate activity against HIV-1 $\left(\mathrm{EC}_{50}>16-\mathrm{m}>59 \mu \mathrm{M}\right)$.
\end{abstract}

Keywords: 2-aminothiazole, 1,2,4-triazol, oxindoles, cytotoxicity, antiviral activity.

\section{Introduction}

The twentieth century has been characterized both by a drastic reduction in the mortality caused by infectious diseases and by a rise in the control of neoplastic pathologies. The treatment of infectious diseases still remains an important and challenging problem. The therapeutic problem has achieved increasing importance in hospitalised patients, in immuno suppressed patients with AIDS or undergoing anticancer therapy and organ transplants. Oxindoles has posses a different kind of physiological activity [1-21]. 4-Aryl-5-(1H-1,2,4-triazol-1-yl)-1,3-thiazol-2-amines are found to be associated with various biological activities such as antifungal, anti-inflammatory, plant-growth regulatory, adenosine receptor antagonists [22-24]. Prompted by these reports and in continuation of search for bioactive substituted thiazole from computer prediction [25] to synthesis and biological evaluation it was contemplated to synthesize 2-aminothiazole containing $1 H$-1,2,4-triazole's moiety starting from 1-benzoylmethyl-1H-1,2,4-triazoles.

\section{Results and discussion}

\subsection{Chemistry}

Recently, we described the synthesis of substituted oxindoles [11,26-32]. In the present paper, the synthesis of 3-hydroxyoxindoles 1-18 from easily accessible [32, 33] indol-2,3-diones 25-35 are suggested (Scheme 1).

Our initial studies $[27,28]$ were performed using as catalyst $\mathrm{Et}_{2} \mathrm{NH}$ in aq. $\mathrm{MeOH}$, aq. EtOH, aq. $i-\mathrm{PrOH}$. The presence of water in reaction media at room temperature showed a positive effect on the reaction of isatine 25 with acetone 19. However, the use of $\mathrm{Et}_{2} \mathrm{NH}$ as a catalyst in $25 \%$ aq. ethylene glycol gives the best result (98\%) compared to using of $\mathrm{Et}_{2} \mathrm{NH}$ in aq. $\mathrm{MeOH}(77 \%)$, aq. $\mathrm{EtOH}(81 \%)$ or aq. $i$-PrOH $(88 \%)$. When the temperature was decreased to $5-10^{\circ} \mathrm{C}$, the 3-hydroxyoxindole 1 was obtained only with $60 \%$. Finally, all the interactions of isatines 26-35 with methylketones 19-24 carried out in 25\% aq. ethylene glycol as a solvent using 1 eq. of $\mathrm{Et}_{2} \mathrm{NH}$ as catalyst at room temperature gave the novel oxindoles 3-8 and known derivatives 1,2,9-18 with moderate to good yields (see Table 1 and experimental part).

The known transformation [34] of 1-methylindoline-2,3-dione 26 into thiosemicarbazone 44 afforded an antiviral drug that works by inhibiting mRNA and protein synthesis, especially in pox viruses. On the other side, the synthetic approach to $\Delta^{2}$-1,3,4-thiadiazoline 56 from thiosemicarbazone $\mathbf{4 6}$ we published early [35]. This prompted us to find new compounds having a thiadiazoline moiety attached to oxindoles. These compounds can be considered as cyclic thiosemicarbazide derivatives as well. 


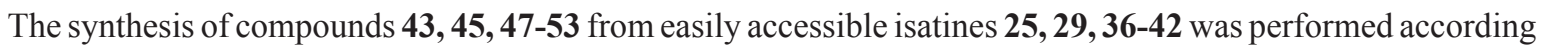
to the method previously reported [35]. Here we report the reaction of 2-oxoindolin-3-ylidene-hydrazinecarbothioamides 43, 45, 47-53 with boiling acetic anhydride (Scheme 1).

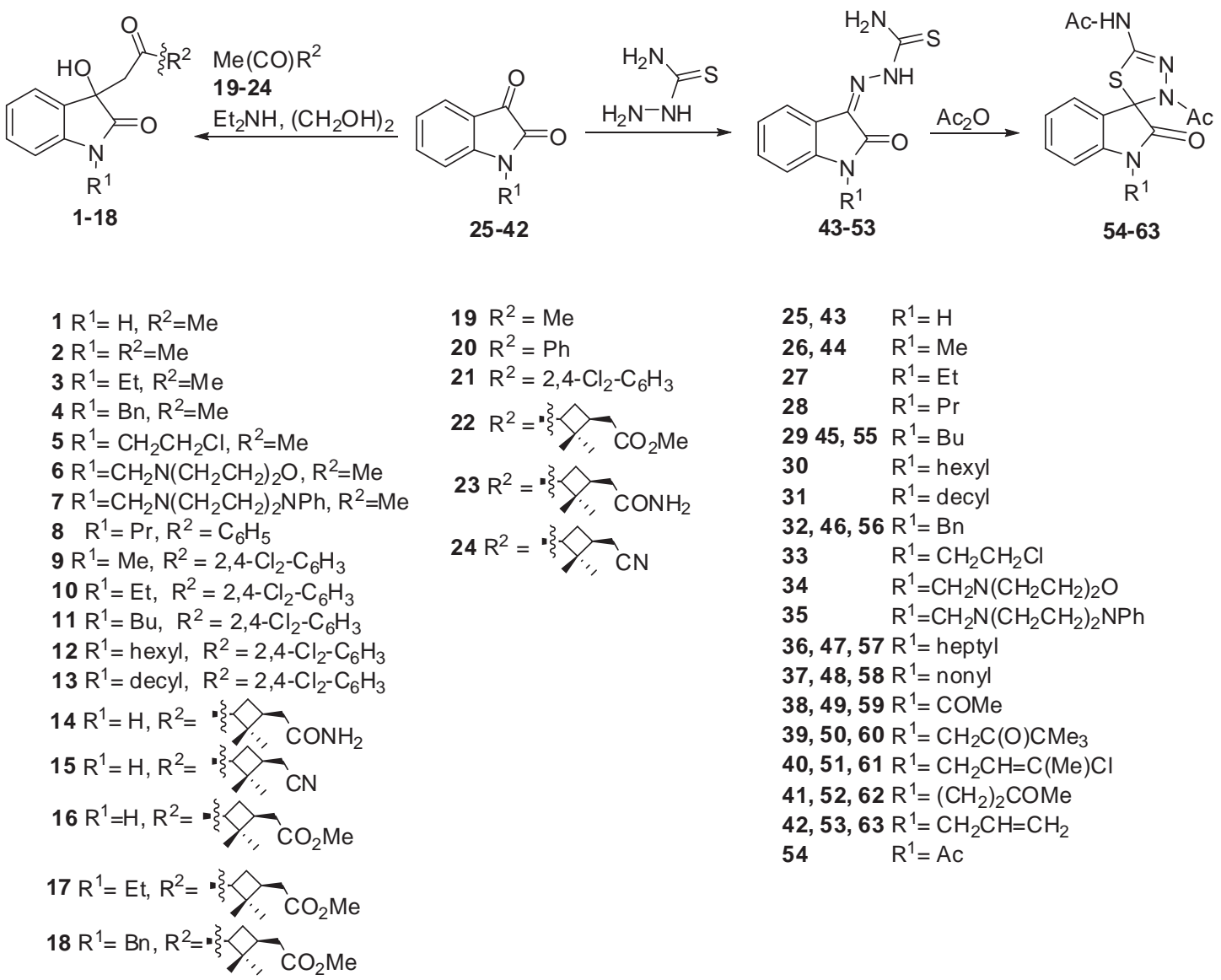

Scheme 1

The reaction of thiosemicarbazone 43 with $\mathrm{Ac}_{2} \mathrm{O}$ at high temperature afforded isatine-derived $\Delta^{2}-1,3,4-$ thiadiazoline 54 as colorless needles in $71 \%$ yield. Similarly, by the reaction of thiosemicarbazone 45, 47-52 and Ac $\mathrm{O}_{2}$, solid spirooxindoles $\mathbf{5 4}, \mathbf{5 5}, \mathbf{5 7 - 6 2}$ were obtained in good to excellent yields (see Table 1).

Table 1

An analytical data of the synthesized compounds

\begin{tabular}{|c|c|c|c|c|c|c|}
\hline \multirow{3}{*}{$\begin{array}{l}\text { Compo } \\
\text { unds }\end{array}$} & \multirow{3}{*}{$\begin{array}{l}\text { Aggregation } \\
\text { M.p. }\left({ }^{\circ} \mathrm{C}\right) \\
\text { from EtOH }\end{array}$} & \multirow{3}{*}{$\begin{array}{l}\text { Yield } \\
(\%)\end{array}$} & \multirow{3}{*}{ Mol. Formula } & \multicolumn{3}{|c|}{ Elemental analyses $(\%)$} \\
\hline & & & & $\mathrm{C}$ & $\mathrm{H}$ & $\mathrm{N}$ \\
\hline & & & & Calcd. / Found & Calcd. /Found & Calcd. / Found \\
\hline 3 & $155-156$ & 76 & $\mathrm{C}_{13} \mathrm{H}_{15} \mathrm{NO}_{3}$ & $66.94 / 67.23$ & $6.48 / 6.67$ & $6.00 / 6.32$ \\
\hline 4 & $155-157$ & 80 & $\mathrm{C}_{18} \mathrm{H}_{17} \mathrm{NO}_{3}$ & $73.20 / 73.44$ & $5.80 / 6.21$ & $4.74 / 4.72$ \\
\hline 5 & $150-152$ & 78 & $\mathrm{C}_{13} \mathrm{H}_{14} \mathrm{ClN}_{2} \mathrm{O}$ & $58.32 / 58.22$ & $5.27 / 5.68$ & $5.23 / 5.48$ \\
\hline 6 & $107-108$ & 76 & $\mathrm{C}_{18} \mathrm{H}_{17} \mathrm{NO}_{3}$ & $73.20 / 73.44$ & $5.80 / 6.21$ & $4.74 / 4.72$ \\
\hline 7 & $165-166$ & 73 & $\mathrm{C}_{16} \mathrm{H}_{20} \mathrm{~N}_{2} \mathrm{O}_{4}$ & $63.14 / 63.22$ & $6.62 / 6.26$ & $9.20 / 9.33$ \\
\hline 8 & $149-150$ & 76 & $\mathrm{C}_{22} \mathrm{H}_{25} \mathrm{~N}_{2} \mathrm{O}_{3}$ & 69.64 / 69.77 & $6.64 / 6.99$ & $11.07 / 10.92$ \\
\hline 43 & 252 & 92 & $\mathrm{C}_{9} \mathrm{H}_{8} \mathrm{~N}_{4} \mathrm{OS}$ & $49.08 / 49.08$ & $3.66 / 3.49$ & $25.44 / 25.27$ \\
\hline 45 & 155 & 91 & $\mathrm{C}_{13} \mathrm{H}_{16} \mathrm{~N}_{4} \mathrm{OS}$ & $56.50 / 56.34$ & $5.84 / 6.02$ & $20.27 / 20.45$ \\
\hline 46 & 250 & 96 & $\mathrm{C}_{16} \mathrm{H}_{14} \mathrm{~N}_{4} \mathrm{OS}$ & $61.92 / 61.77$ & $4.55 / 4.68$ & $18.05 / 18.34$ \\
\hline 47 & $166-168$ & 90 & $\mathrm{C}_{15} \mathrm{H}_{20} \mathrm{~N}_{4} \mathrm{OS}$ & $59.18 / 59.00$ & $6.62 / 6.49$ & $18.40 / 18.11$ \\
\hline 48 & $131-132$ & 88 & $\mathrm{C}_{18} \mathrm{H}_{26} \mathrm{~N}_{4} \mathrm{OS}$ & $62.39 / 62.22$ & $7.56 / 7.33$ & $16.17 / 16.01$ \\
\hline 49 & $251-254$ & 97 & $\mathrm{C}_{12} \mathrm{H}_{12} \mathrm{~N}_{4} \mathrm{O}_{2} \mathrm{~S}$ & $52.16 / 51.89$ & $4.38 / 4.55$ & $20.28 / 20.11$ \\
\hline 50 & $236-237$ & 82 & $\mathrm{C}_{15} \mathrm{H}_{18} \mathrm{~N}_{4} \mathrm{O}_{2} \mathrm{~S}$ & $56.58 / 56.38$ & $5.70 / 5.56$ & $17.60 / 17.46$ \\
\hline 51 & 228 & 79 & $\mathrm{C}_{13} \mathrm{H}_{13} \mathrm{ClN}_{4} \mathrm{OS}$ & $50.57 / 50.69$ & $4.24 / 4.47$ & $18.14 / 18.11$ \\
\hline
\end{tabular}




\begin{tabular}{|c|c|c|c|c|c|c|}
\hline 52 & $203-205$ & 77 & $\mathrm{C}_{13} \mathrm{H}_{14} \mathrm{~N}_{4} \mathrm{OS}$ & $53.78 / 54.09$ & $4.86 / 5.02$ & $19.30 / 19.10$ \\
\hline 53 & $176-178$ & 81 & $\mathrm{C}_{12} \mathrm{H}_{12} \mathrm{~N}_{4}^{4} \mathrm{OS}$ & $55.37 / 55.21$ & $4.65 / 4.69$ & $21.52 / 21.63$ \\
\hline 54 & $246-248$ & 71 & $\mathrm{C}_{13} \mathrm{H}_{12} \mathrm{~N}_{4} \mathrm{O}_{3} \mathrm{~S}$ & $51.31 / 51.59$ & $3.97 / 4.25$ & $18.41 / 18.66$ \\
\hline 55 & $211-213$ & 65 & $\mathrm{C}_{17} \mathrm{H}_{20} \mathrm{~N}_{4} \mathrm{O}_{3} \mathrm{~S}$ & $56.65 / 56.66$ & $5.59 / 5.77$ & $15.54 / 15.34$ \\
\hline 56 & $248-249$ & 88 & $\mathrm{C}_{20} \mathrm{H}_{18} \mathrm{~N}_{4} \mathrm{O}_{3} \mathrm{~S}$ & $60.90 / 60.88$ & $4.60 / 4.44$ & $14.20 / 14.32$ \\
\hline 57 & $170-171$ & 71 & $\mathrm{C}_{19} \mathrm{H}_{24} \mathrm{~N}_{4} \mathrm{O}_{3} \mathrm{~S}$ & $58.74 / 58.77$ & $6.23 / 6.50$ & $14.42 / 14.65$ \\
\hline 58 & $202-203$ & 70 & $\mathrm{C}_{22} \mathrm{H}_{30} \mathrm{~N}_{4} \mathrm{O}_{3} \mathrm{~S}$ & $61.37 / 61.55$ & $7.02 / 7.32$ & $13.01 / 12.96$ \\
\hline 59 & 247 & 59 & $\mathrm{C}_{16} \mathrm{H}_{16} \mathrm{~N}_{4} \mathrm{O}_{4} \mathrm{~S}$ & $53.32 / 53.61$ & $4.47 / 4.35$ & $14.20 / 14.20$ \\
\hline 60 & $250($ decom $)$ & 82 & $\mathrm{C}_{19} \mathrm{H}_{22} \mathrm{~N}_{4} \mathrm{O}_{4} \mathrm{~S}$ & $56.70 / 56.55$ & $5.51 / 5.69$ & $13.92 / 14.12$ \\
\hline 61 & $176-178$ & 60 & $\mathrm{C}_{17} \mathrm{H}_{17} \mathrm{ClN}_{4} \mathrm{O}_{3} \mathrm{~S}$ & $51.97 / 51.84$ & $4.36 / 4.54$ & $14.26 / 14.02$ \\
\hline 62 & 189-192 & 57 & $\mathrm{C}_{17} \mathrm{H}_{18} \mathrm{~N}_{4} \mathrm{O}_{4} \mathrm{~S}$ & $54.53 / 54.59$ & $4.85 / 4.68$ & $14.96 / 14.89$ \\
\hline 63 & $173-175$ & 40 & $\mathrm{C}_{16} \mathrm{H}_{16} \mathrm{~N}_{4} \mathrm{O}_{3} \mathrm{~S}$ & $55.80 / 55.98$ & $4.68 / 4.41$ & $16.27 / 16.45$ \\
\hline 70 & $162-163$ & 75 & $\mathrm{C}_{11} \mathrm{H}_{12} \mathrm{~N}_{6} \mathrm{~S}$ & $50.75 / 50.97$ & $4.65 / 4.83$ & $32.28 / 32.55$ \\
\hline 71 & 194-199 & 66 & $\mathrm{C}_{12} \mathrm{H}_{14} \mathrm{~N}_{6} \mathrm{~S}$ & $52.54 / 52.66$ & $5.14 / 5.33$ & $30.63 / 30.76$ \\
\hline 72 & $187-190$ & 79 & $\mathrm{C}_{11} \mathrm{H}_{10} \mathrm{Cl}_{2} \mathrm{~N}_{6} \mathrm{~S}$ & $40.13 / 40.34$ & $3.06 / 3.06$ & $25.53 / 25.67$ \\
\hline 73 & $226-236$ & 50 & $\mathrm{C}_{15} \mathrm{H}_{16} \mathrm{~N}_{6} \mathrm{O}_{2} \mathrm{~S}$ & $52.31 / 52.33$ & $4.68 / 4.77$ & $24.40 / 24.23$ \\
\hline 74 & 199 & 56 & $\mathrm{C}_{16} \mathrm{H}_{18} \mathrm{~N}_{6} \mathrm{O}_{2} \mathrm{~S}$ & $53.65 / 53.44$ & $5.07 / 4.77$ & $24.40 / 23.37$ \\
\hline 75 & 250 (decom) & 63 & $\mathrm{C}_{15} \mathrm{H}_{14} \mathrm{Cl}_{2} \mathrm{~N}_{6} \mathrm{O}_{2} \mathrm{~S}$ & $43.59 / 43.52$ & $3.41 / 3.49$ & $20.33 / 20.31$ \\
\hline 77 & $230-232$ & 89 & $\mathrm{C}_{11} \mathrm{H}_{8} \mathrm{BrN}_{3} \mathrm{~S}$ & C 41.01/40.98 & $2.50 / 2.71$ & $21.74 / 21.72$ \\
\hline 78 & $245-246$ & 88 & $\mathrm{C}_{11} \mathrm{H}_{8} \mathrm{ClN}_{5} \mathrm{~S}$ & $47.57 / 47.83$ & $2.90 / 2.59$ & $25.22 / 25.03$ \\
\hline 79 & $250($ decom $)$ & 93 & $\mathrm{C}_{12} \mathrm{H}_{11} \mathrm{ClN}_{5} \mathrm{~S}$ & $56.01 / 56.21$ & $4.31 / 4.00$ & $27.22 / 27.47$ \\
\hline 80 & $243-244$ & 77 & $\mathrm{C}_{11} \mathrm{H}_{7} \mathrm{Cl}_{2} \mathrm{~N}_{5} \mathrm{~S}$ & $42.32 / 41.98$ & $2.26 / 2.08$ & $22.43 / 22.65$ \\
\hline 81 & $285-286$ & 77 & $\mathrm{C}_{13} \mathrm{H}_{11} \mathrm{Cl}_{2} \mathrm{~N}_{5} \mathrm{~S}$ & $45.89 / 46.32$ & $3.26 / 3.11$ & $20.58 / 20.68$ \\
\hline
\end{tabular}

$\mathrm{N}$-Allylisatine derivative 53 readily underwent cyclization with $\mathrm{Ac}_{2} \mathrm{O}$ to produce the corresponding 1,3,4-thiadiazoline 63. This compound also appeared to be quite stable in the reaction mixture at this temperature. However, acetamide $\mathbf{6 3}$ was obtained in a low yield (only a $40 \%$ ). At this condition polymerization to a dark solid material was observed.

The successfull use of thiosemicarbazones in heterocyclization encouraged us to apply available 1-aryl-2-(1H1,2,4-triazol-1-yl)-1-ethanones $\mathbf{6 6 , 6 8 , 6 9}$ [36] for the synthesis of compounds $\mathbf{7 0 - 7 2}$ (schema 2).

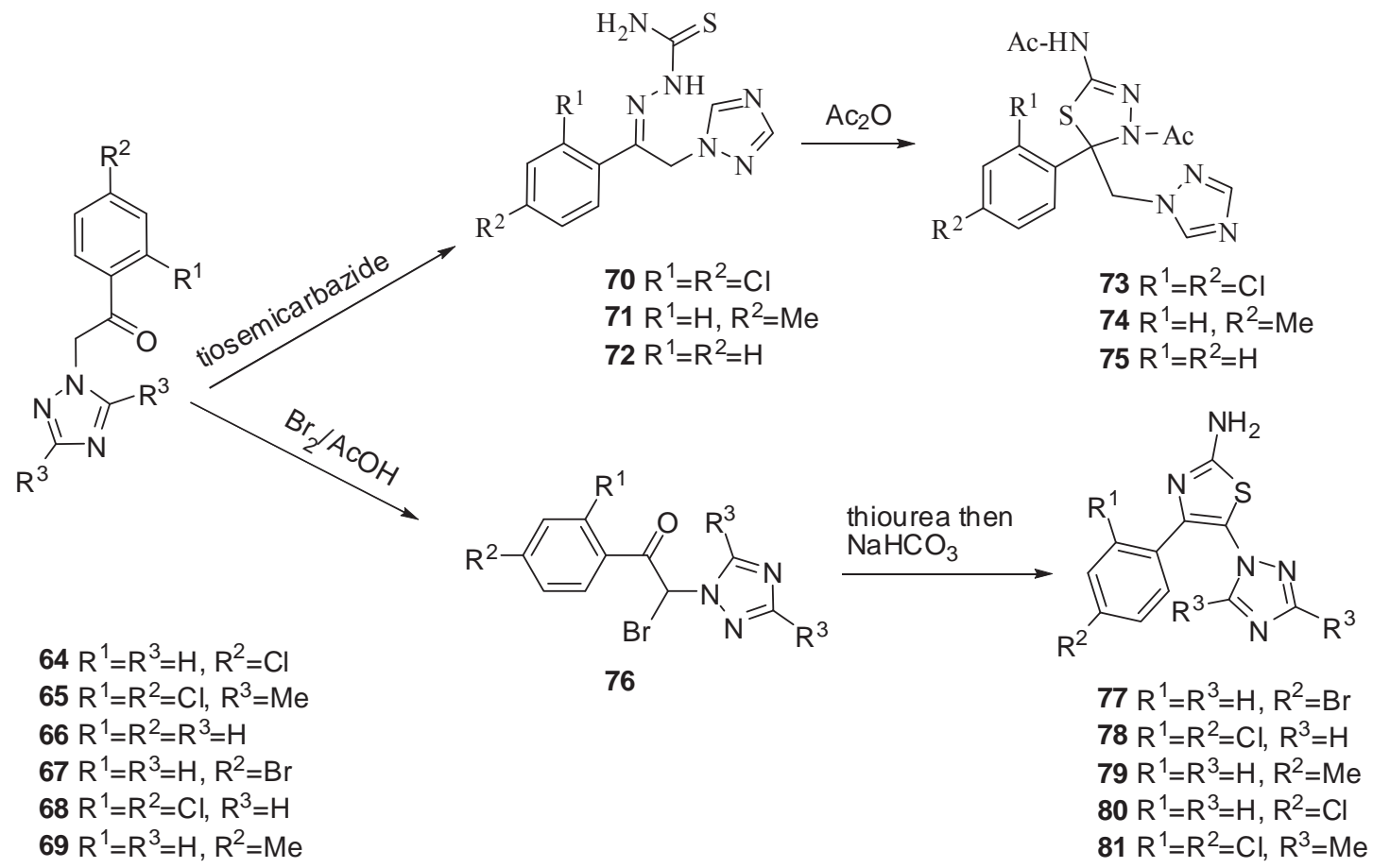

Scheme 2

The thiosemicarbazones 70-72 when reacted with boiling acetic anhydride gave variable yields of 2-acetamido4-acetyl-5-(aryl)-5-(1H-1,2,4-triazol-1-yl-methyl)- $\Delta^{2}$-1,3,4-thiadiazoline 73-75. 
The second strategy has include transformations of ethanones 64, 65, and 67-69 into the 1,3-thiazol-2-amines derivative 1,2,4-triazoles 77-81 via corresponding $\alpha$-bromoketones $\mathbf{7 6}$. In the beginning our study the compound $\mathbf{7 6}$ $\left(\mathrm{R}^{1}=\mathrm{R}^{3}=\mathrm{H}, \mathrm{R}^{2}=\mathrm{Br}\right)$ was obtained by the halogenation of ketone 67 with $\mathrm{Br}_{2}$ in mixture $\mathrm{HBr} / \mathrm{AcOH}$ at $10^{\circ} \mathrm{C}$ according to the procedure described in the literature [37]. However, this compound was apparently not very stable. It is worth noting that allylic bromination of ketone 67 using $\mathrm{Br}_{2}$ followed by condensation of product with thiourea gave the 2-aminothiazole 77 in $89 \%$ yield. The optimized two steps protocol was then expanded to ketones $\mathbf{6 4 , 6 5 , 6 8 , ~ a n d ~} \mathbf{6 9}$. The targets 2-aminothiazole-1H-1,2,4-triazoles 78-81 were conveniently isolated as precipitates with good yields (see Table 1). All synthesized compounds were characterized by ellemental analysis (Table 1) as well as spectroscopically (H-NMR, Table 2, MS experimental part).

${ }^{1}$ H NMR spectral data of synthesized compounds

Table 2

\footnotetext{
$\delta(\mathrm{ppm})$

\begin{tabular}{cc} 
Comp. & $\delta(\mathrm{ppm})$ \\
\hline 3 & DMSO-d $: 1.20\left(\mathrm{t}, 3 \mathrm{H}, \mathrm{J}=9.17, \mathrm{CH}_{3} \mathrm{CH}_{2}\right) ; 2.10(\mathrm{~s}, 3 \mathrm{H}, \mathrm{Me}) ; 2.97\left(\mathrm{dd}, 2 \mathrm{H}, \mathrm{CH}_{2}, \mathrm{AB}-\right.$ system, $J=11.20$ and 14.49$)$,
\end{tabular} 4.80 (q, $\left.2 \mathrm{H}, \mathrm{J}=6.48 \mathrm{~Hz}, \mathrm{MeCH}_{2}\right) ; 4.39$ (s, 1H, OH), 6.81-7.44 (m, 4H, ArH)

4 DMSO-d $_{6}: 2.11(\mathrm{~s}, 3 \mathrm{H}, \mathrm{Me}) ; 2.89,2.99\left(\mathrm{dd}, 2 \mathrm{H}, \mathrm{CH}_{2}, \mathrm{AB}-\mathrm{system}, \mathrm{J}=11.55\right.$ and 24.32); 4.48 (s, $\left.1 \mathrm{H}, \mathrm{OH}\right) ; 4.88(\mathrm{~s}$, $\left.2 \mathrm{H}, \mathrm{N}-\underline{\mathrm{CH}}_{2}-\mathrm{Ph}\right) ; 6.24-7.41$ (м, 9H, arom).

$5 \mathrm{CDCl}_{3}: 2.14(\mathrm{~s}, 3 \mathrm{H}, \mathrm{Me}) ; 3.11-3.66\left(\mathrm{~m}, 3 \mathrm{CH}_{2}\right) ; 3.97(\mathrm{~s}, 1 \mathrm{H}, \mathrm{OH}) ; 6.91-7.23(\mathrm{M}, 4 \mathrm{H}$, arom).

6 DMSO-d $_{6}: 2.09(\mathrm{~s}, 3 \mathrm{H}, \mathrm{Me}) ; 2.50-3.65\left(\mathrm{~m}, 3 \mathrm{CH}_{2}\right) ; 4.41\left(\mathrm{~s}, 2 \mathrm{H}, \mathrm{NCH}_{2}\right), 6.08(\mathrm{~s}, 1 \mathrm{H}, \mathrm{OH}) ; 6.77-7.11(\mathrm{M}, 4 \mathrm{H}$, arom).

$7 \mathrm{CDCl}_{3}: 2.17(\mathrm{~s}, 3 \mathrm{H}, \mathrm{Me}) ; 2.48-3.44\left(\mathrm{~m}, 3 \mathrm{CH}_{2}\right) ; 4.58(\mathrm{~s}, 1 \mathrm{H}, \mathrm{OH}) ; 4.45\left(\mathrm{~s}, 2 \mathrm{H}, \mathrm{NCH}_{2}\right), 6.43-7.27$ (м, 9H, arom).

$8 \mathrm{CDCl}_{3}: 0.90\left(\mathrm{t}, 3 \mathrm{H}, \mathrm{J}=8.7, \mathrm{CH}_{3} \mathrm{CH}_{2}\right) ; 1.62-3.38\left(\mathrm{~m}, 4 \mathrm{H}, 2 \mathrm{CH}_{2}\right), 2.06(\mathrm{~s}, 3 \mathrm{H}, \mathrm{Me}) ; 2.76\left(\mathrm{dd}, 2 \mathrm{H}, \mathrm{CH}_{2}, \mathrm{AB}-\mathrm{system}\right.$, $J=11.01$ and 14.49), $5.99(\mathrm{~s}, 1 \mathrm{H}, \mathrm{OH}), 6.83-7.98(\mathrm{~m}, 4 \mathrm{H}, \mathrm{ArH})$

43 DMSO-d 6 : 7.23-7.89 (m, 6H, NH, $\mathrm{ArH}) ; 9.10$ (s, 1H, NH-CO); 11.13 (s, 1H, NH-CS)

45 DMSO-d $_{6}: 1.00\left(\mathrm{t}, 3 \mathrm{H}, \mathrm{J}=8.76, \mathrm{C}_{3} \mathrm{CH}_{2}\right) ; 1.31-3.97\left(\mathrm{~m}, 6 \mathrm{H}, 3 \mathrm{CH}_{2}\right) ; 7.21-7.98\left(\mathrm{~m}, 6 \mathrm{H}, \mathrm{NH}_{2}, \mathrm{ArH}\right), 10.92(\mathrm{~s}, 1 \mathrm{H}$, $\mathrm{NH}-\mathrm{CS})$

46 DMSO-d $: 4.94\left(\mathrm{~s}, 2 \mathrm{H}, \mathrm{CH}_{2}\right) ; 6.93-7.75$ (m, 9H, ArH); 8.74-9.10 (m, 2H, NH$)$ ); 12.43 (s, 1H, NH-CS)

$47 \mathrm{CDCl}_{3}: 0.78\left(\mathrm{t}, 3 \mathrm{H}, \mathrm{CH}_{2}-\underline{\mathrm{C}}_{3}, J=7.28\right) ; 1.02-1.79\left(\mathrm{~m}, 6 \mathrm{H},\left(\mathrm{CH}_{2}\right)_{3}\right) ; 3.64\left(\mathrm{q}, 2 \mathrm{H}, \mathrm{CH}_{2}-\mathrm{N}, J=7.14\right)$

$48 \mathrm{CDCl}_{3}: 0.78\left(\mathrm{t}, 3 \mathrm{H}, \mathrm{CH}_{2}-\underline{\mathrm{CH}}_{3}, J=5.76\right) ; 1.0-1.83\left(\mathrm{~m}, 14 \mathrm{H},\left(\mathrm{C}_{2}\right)_{7}\right) ; 3.64\left(\mathrm{t}, 2 \mathrm{H}, \mathrm{CH}_{2}-\mathrm{N}, J=7.28\right) ; 6.65-7.54$ (m, $\left.5 \mathrm{H}, \mathrm{ArH}, \mathrm{NH}_{2}\right) ; 12.26(\mathrm{~s}, 1 \mathrm{H}, \mathrm{N} \underline{\mathrm{H}}-\mathrm{CS})$

$49 \mathrm{DMSO}_{-}$: $2.11\left(\mathrm{~s}, 3 \mathrm{H}, \mathrm{COCH}_{3}\right) ; 2.85\left(\mathrm{t}, 2 \mathrm{H}, \mathrm{CH}_{2}-\mathrm{CO}-\mathrm{CH}_{3}, J=7.28\right) ; 3.89\left(\mathrm{t}, 2 \mathrm{H}, \mathrm{N}-\mathrm{C}_{2}-\mathrm{CH}_{2}, J=7.2\right) ; 7.00-7.70$ (m, 4H, ArH); 8.65-9.05 (m, 2H, $\left.\mathrm{NH}_{2}\right) ; 12.36$ (s, 1H, NH-CS)

50 DMSO-d ${ }_{6}: 1.20\left(\mathrm{~s}, 9 \mathrm{H}, 3 \mathrm{CH}_{3}\right) ; 4.80\left(\mathrm{~s}, 2 \mathrm{H}_{2} \mathrm{CH}_{2}\right) ; 6.69-7.76(\mathrm{~m}, 4 \mathrm{H}, \mathrm{ArH}) ; 8.71,8.08\left(\mathrm{~s}, \mathrm{~s}, 2 \mathrm{H}, \mathrm{NH}_{2}\right) ; 12.29(\mathrm{~s}, 1 \mathrm{H}, \mathrm{NH})$

51 DMSO-d $: 2.11\left(\mathrm{~s}, 3 \mathrm{H}, \mathrm{CH}_{3}\right) ; 4.42\left(\mathrm{~d}, 2 \mathrm{H}, \mathrm{CH}_{2}, J=6.06\right) ; 5.72(\mathrm{t}, 1 \mathrm{H}, \mathrm{CH}=,, J=6.29), 6.93-7.72(\mathrm{~m}, 4 \mathrm{H}, \mathrm{ArH})$; 8.67, 8.9.06 (s, s, 2H, $\left.\mathrm{NH}_{2}\right) ; 12.34(\mathrm{~s}, 1 \mathrm{H}, \mathrm{NH})$

$52 \mathrm{CDCl}_{3}: 2.13(\mathrm{~s}, 3 \mathrm{H}, \mathrm{Me}) ; 2.70-3.24\left(\mathrm{~m}, 2 \mathrm{CH}_{2}\right) ; 7.21-7.98\left(\mathrm{~m}, 6 \mathrm{H}, \mathrm{NH}_{2}, \mathrm{ArH}\right), 10.92(\mathrm{~s}, 1 \mathrm{H}, \mathrm{NH}-\mathrm{CS})$

53 DMSO$_{-}$: $4.32\left(\mathrm{~s}, 2 \mathrm{H}, \mathrm{CH}_{2}\right)$; 4.89-5.39 (m, 2H, $\left.=\mathrm{CH}_{2}\right), 5.49-6.2(\mathrm{~m}, 1 \mathrm{H}, \mathrm{CH}=)$, 6.97-7.73 (m, 4H, $\left.\mathrm{ArH}\right) ; 8.59$, $8.9 .03\left(\mathrm{~s}, \mathrm{~s}, 2 \mathrm{H}, \mathrm{NH}_{2}\right) ; 12.45(\mathrm{~s}, 1 \mathrm{H}, \mathrm{NH})$

54 DMSO-d $_{6}: 2.1,2.15\left(\mathrm{~s}, \mathrm{~s}, 6 \mathrm{H}, 2 \mathrm{COCH}_{3}\right) ; 2.56\left(\mathrm{~s}, 3 \mathrm{H}, \mathrm{CONCOCH}_{3}\right) ; 6.65-7.5(\mathrm{~m}, 4 \mathrm{H}, \mathrm{ArH}) ; 12.05(\mathrm{~s}, 1 \mathrm{H}, \mathrm{NH})$

$55 \mathrm{CDCl}_{3}: 0.812\left(\mathrm{t}, 3 \mathrm{H}, \mathrm{CH}_{2}-\mathrm{C}_{3}, J=6.28\right) ; 1.13-1.64\left(\mathrm{~m}, 4 \mathrm{H}, \mathrm{CH}_{2}-\mathrm{C}_{2}-\mathrm{CH}_{3}\right) ; 1.91,2.13\left(\mathrm{~s}, \mathrm{~s}, 6 \mathrm{H}, 2 \mathrm{COCH}_{3}\right) ; 3.69$ $\left(\mathrm{t}, 2 \mathrm{H}, \mathrm{N}-\mathrm{CH}_{2}, \mathrm{~J}=6.51\right) ; 6.74-7.39(\mathrm{~m}, 4 \mathrm{H}, \mathrm{ArH}) ; 10.40(\mathrm{~s}, 1 \mathrm{H}, \mathrm{NH})$

56 DMSO-d $: 2.08\left(\mathrm{~s}, \mathrm{~s}, 6 \mathrm{H}, 2 \mathrm{COCH}_{3}\right) ; 2.21\left(\mathrm{c}, 3 \mathrm{H}, \mathrm{CO}-\mathrm{CH}_{3}\right), 4.94\left(\mathrm{q}, 2 \mathrm{H}, \mathrm{J}-16.11, \mathrm{~N}-\mathrm{CH}_{2}-\mathrm{C}_{6} \mathrm{H}_{5}\right) ; 6.73-7.45(\mathrm{M}$, 9H, аром); 12.00 (c, $\left.1 \mathrm{H}, \mathrm{NH}-\mathrm{CO}-\mathrm{CH}_{3}\right)$

$57 \mathrm{CDCl}_{3}: 0.80\left(\mathrm{t}, 3 \mathrm{H}, \mathrm{CH}_{2}-\underline{\mathrm{CH}}_{3}, J=5.49\right) ; 1.15-1.65\left(\mathrm{~m}, 8 \mathrm{H},\left(\underline{\mathrm{CH}}_{2}\right)_{4} \mathrm{Me}\right) ; 1.92\left(\mathrm{~s}, 3 \mathrm{H}, \mathrm{COCH}_{3}\right), 2.12\left(\mathrm{~s}, 3 \mathrm{H}, \mathrm{COCH}_{3}\right)$; 3.67 (t, 2H, N- $\left.\mathrm{CH}_{2}, J=6.91\right) ; 6.73-7.38(\mathrm{~m}, 4 \mathrm{H}, \mathrm{ArH}) ; 10.40(\mathrm{~s}, 1 \mathrm{H}, \mathrm{NH})$

$58 \mathrm{CDCl}_{3}: 0.80\left(\mathrm{t}, 3 \mathrm{H}, \mathrm{CH}_{2}-\mathrm{CH}_{3}, J=6.64\right) ; 1.21-1.84\left(\mathrm{~m}, 14 \mathrm{H},\left(\mathrm{CH}_{2}\right)_{7} \mathrm{Me}\right) ; 1.93\left(\mathrm{~s}, 3 \mathrm{H}, \mathrm{COCH}_{3}\right) ; 2.13\left(\mathrm{~s}, 3 \mathrm{H}, \mathrm{COCH}_{3}\right)$; $3.67\left(\mathrm{t}, 2 \mathrm{H}, \mathrm{N}-\mathrm{CH}_{2}, \mathrm{~J}=6.69\right) ; 6.74-7.39(\mathrm{~m}, 4 \mathrm{H}, \mathrm{ArH}) ; 10.35(\mathrm{~s}, 1 \mathrm{H}, \mathrm{NH})$

$59 \mathrm{CDCl}_{3}: 2.1,2.16,2.22\left(\mathrm{~s}, \mathrm{~s}, \mathrm{~s}, 9 \mathrm{H}, 3 \mathrm{COCH}_{3}\right) ; 4.67\left(\mathrm{~s}, 2 \mathrm{H}, \mathrm{CH}_{2}\right) ; 6.68-7.36(\mathrm{~m}, 4 \mathrm{H}, \mathrm{ArH}) ; 11.72(\mathrm{~s}, 1 \mathrm{H}, \mathrm{NH})$

60 DMSO-d $_{6}: 1.19\left(\mathrm{~s}, 9 \mathrm{H}, \mathrm{CMe}_{3}\right) ; 2.08,2.14\left(\mathrm{~s}, \mathrm{~s} 6 \mathrm{H}, 2 \mathrm{COCH}_{3}\right) ; 4.83\left(\mathrm{~s}, 2 \mathrm{H}_{,} \mathrm{CH}_{2}\right) ; 6.79-7.43(\mathrm{~m}, 4 \mathrm{H}, \mathrm{ArH})$

$61 \mathrm{CDCl}_{3}: 1.08\left(\mathrm{~s}, 3 \mathrm{H},=\mathrm{C}-\mathrm{CH}_{3}\right) ; 1.96,2.12\left(\mathrm{~s}, \mathrm{~s}, 6 \mathrm{H}, 2 \mathrm{COCH}_{3}\right) ; 4.45\left(\mathrm{~d}, 2 \mathrm{H}, \mathrm{CH}_{2}, J=7.21\right) ; 5.45(\mathrm{t}, 1 \mathrm{H}, \mathrm{CH}=\mathrm{C}$, $J=7.07) ; 6.74-7.38(\mathrm{~m}, 4 \mathrm{H}, \mathrm{ArH}) ; 10.17(\mathrm{~s}, 1 \mathrm{H}, \mathrm{NH})$

$62 \mathrm{CDCl}_{3}: 1.97,2.02\left(\mathrm{~s}, \mathrm{~s}, 6 \mathrm{H}, 2 \mathrm{COCH}_{3}\right) ; 2.05\left(\mathrm{~s}, 3 \mathrm{H}, \mathrm{COCH}_{3}\right) ; 2.73\left(\mathrm{t}, 2 \mathrm{H}, \mathrm{CH}_{2} \mathrm{CO}, J=7.4\right) ; 3.82\left(\mathrm{t}, 2 \mathrm{H}, \mathrm{N}-\mathrm{CH}_{2}\right.$, $J=7.6) ; 6.69-7.28(\mathrm{~m}, 4 \mathrm{H}, \mathrm{ArH}) ; 11.06(\mathrm{~s}, 1 \mathrm{H}, \mathrm{NH})$

63 DMSO-d $_{6}: 2.09,2.2 .16\left(\mathrm{~s}, \mathrm{~s}, 6 \mathrm{H}, 2 \mathrm{COCH}_{3}\right) ; 4.20-4.39\left(\mathrm{~m}, 2 \mathrm{H}, \mathrm{CH}_{2}\right) ; 4.89-5.48\left(\mathrm{~m}, 2 \mathrm{H},=\mathrm{CH}_{2}\right), 5.63-5.89(\mathrm{~m}, 1 \mathrm{H}$, $\mathrm{CH}=)$, 6.88-7.59 (m, $4 \mathrm{H}, \mathrm{ArH}) ; 12.03(\mathrm{~s}, 1 \mathrm{H}, \mathrm{NH})$

70 DMSO-d $_{6}: 5.71\left(\mathrm{~s}, 2 \mathrm{H}, \mathrm{CH}_{2}\right) ; 7.36(\mathrm{~m}, 5 \mathrm{H}, \mathrm{ArH}) ; 7.93\left(\mathrm{~s}, 1 \mathrm{H}\right.$, triazole $\left.\mathrm{C}_{(3)} \mathrm{H}\right) ; 8.12-8.52\left(\mathrm{~m}, 2 \mathrm{H}, \mathrm{NH}_{2}\right) ; 8.68(\mathrm{~s}$, $1 \mathrm{H}$, triazole $\left.\mathrm{C}_{(5)} \mathrm{H}\right) ; 10.97(\mathrm{~s}, 1 \mathrm{H}, \mathrm{NH})$
} 
71 DMSO-d $_{6}: 2.26\left(\mathrm{~s}, 3 \mathrm{H}, \mathrm{CH}_{3}\right) ; 5.69\left(\mathrm{~s}, 2 \mathrm{H}, \mathrm{CH}_{2}\right) ; 7.09-7.68(\mathrm{~m}, 4 \mathrm{H}, \mathrm{ArH}) ; 7.94\left(\mathrm{~s}, 1 \mathrm{H}\right.$, triazole $\left.\mathrm{C}_{(3)} \mathrm{H}\right) ; 8.09-8.44$ $\left(\mathrm{m}, 2 \mathrm{H}, \mathrm{NH}_{2}\right) ; 8.66\left(\mathrm{~s}, 1 \mathrm{H}\right.$, triazole $\left.\mathrm{C}_{(5)} \mathrm{H}\right) ; 10.94(\mathrm{~s}, 1 \mathrm{H}, \mathrm{NH})$

72 DMSO-d $_{6}: 5.29\left(\mathrm{~s}, 2 \mathrm{H}, \mathrm{CH}_{2}\right) ; 6.98-8.48\left(\mathrm{~m}, 5 \mathrm{H}, \mathrm{ArH}, \mathrm{NH}_{2}\right) ; 7.92\left(\mathrm{~s}, 1 \mathrm{H}\right.$, triazole $\left.\mathrm{C}_{(3)} \mathrm{H}\right) ; 8.48\left(\mathrm{~s}, 1 \mathrm{H}\right.$, triazole $\mathrm{C}_{(5)}$ $\mathrm{H}) ; 10.21(\mathrm{~s}, 1 \mathrm{H}, \mathrm{NH})$

73 DMSO-d $:$ 1.93, $2.17\left(\mathrm{~s}, \mathrm{~s}, 6 \mathrm{H}, 2 \mathrm{COCH}_{3}\right) ; 5.30,5.36\left(\mathrm{~d}, \mathrm{~d}, 2 \mathrm{H}, \mathrm{CH}_{2}, \mathrm{AB}\right.$ system, $J=14.43$ and 23); $7.41(\mathrm{~m}, 5 \mathrm{H}$, $\operatorname{ArH}) ; 8.01\left(\mathrm{~s}, 1 \mathrm{H}\right.$, triazole $\left.\mathrm{C}_{(3)} \mathrm{H}\right) ; 8.55\left(\mathrm{~s}, 1 \mathrm{H}\right.$, triazoile $\left.\mathrm{C}_{(5)} \mathrm{H}\right) ; 11.55(\mathrm{~s}, 1 \mathrm{H}, \mathrm{NH})$

74 DMSO-d $_{6}: 1.94,2.16\left(\mathrm{~s}, \mathrm{~s}, 6 \mathrm{H}, 2 \mathrm{COCH}_{3}\right) ; 5.24,5.31\left(\mathrm{~d}, \mathrm{~d}, 2 \mathrm{H}, \mathrm{CH}_{2}, \mathrm{AB}\right.$ system, $J=18.67$ and 28.92); $7.20,7.34$ $(\mathrm{d}, \mathrm{d}, 4 \mathrm{H}, \mathrm{ArH}, J=8.65) ; 8.00\left(\mathrm{~s}, 1 \mathrm{H}\right.$, triazole $\left.\mathrm{C}_{(3)} \mathrm{H}\right) ; 8.54\left(\mathrm{~s}, 1 \mathrm{H}\right.$, triazole $\left.\mathrm{C}_{(5)} \mathrm{H}\right) ; 11.50(\mathrm{~s}, 1 \mathrm{H}, \mathrm{NH})$

75 DMSO-d D $_{6}$ 1.97, $2.07\left(\mathrm{~s}, \mathrm{~s}, 6 \mathrm{H}, 2 \mathrm{COCH}_{3}\right) ; 5.25,5.32\left(\mathrm{~d}, \mathrm{~d}, 2 \mathrm{H}, \mathrm{CH}_{2}, \mathrm{AB}\right.$ system, $J=18.67$ and 25.79); 7.54-7,66 $(\mathrm{m}, 3 \mathrm{H}, \mathrm{ArH}) ; 8.01\left(\mathrm{~s}, 1 \mathrm{H}\right.$, triazole $\left.\mathrm{C}_{(3)} \mathrm{H}\right) ; 8.55\left(\mathrm{~s}, 1 \mathrm{H}\right.$, triazole $\left.\mathrm{C}_{(5)} \mathrm{H}\right) ; 11,55(\mathrm{~s}, 1 \mathrm{H}, \mathrm{NH})$

77 DMSO-d $\mathrm{d}_{6}$ : 7.31-7.67 m (6H, $\mathrm{NH}_{2}$, arom), $8.11 \mathrm{~s}, 8.45 \mathrm{~s}(2 \mathrm{H}, 2 \mathrm{Tr}-\mathrm{H})$.

78 DMSO-d $:$ : 7.18-7.40 m (6H, $\mathrm{NH}_{2}$ arom), $8.18 \mathrm{~s}, 8.56 \mathrm{~s}(2 \mathrm{H}, 2 \mathrm{Tr}-\mathrm{H})$.

79 DMSO-d $_{6}: 2.26 \mathrm{~s}(3 \mathrm{H}, \mathrm{Me}), 7.05$ broad s $(4 \mathrm{H}$, arom $), 7.3 \mathrm{~s}\left(2 \mathrm{H}, \mathrm{NH}_{2}\right), 8.15 \mathrm{~s}, 8.47 \mathrm{~s}(2 \mathrm{H}, 2 \mathrm{Tr}-\mathrm{H})$

80 DMSO-d $\mathrm{d}_{6}$ : 7.23-7.51 m $\left(5 \mathrm{H}, \mathrm{NH}_{2}\right.$, arom $), 7.97 \mathrm{~s}, 8.51 \mathrm{~s}(2 \mathrm{H}, 2 \mathrm{Tr}-\mathrm{H})$

81 DMSO-d 6 : $2.00 \mathrm{~s}, 2.18 \mathrm{~s}(6 \mathrm{H}, 2 \mathrm{Me}), 7.20-7.50 \mathrm{~m}\left(5 \mathrm{H}, \mathrm{NH}_{2}\right.$, arom $)$

\subsection{Antiviral activity}

The synthesized thiazole/triazol/oxindols/thiosemicarbazones were evaluated in vitro in parallel cell-based assays for cytotoxicity and antiviral activity (Tables 4) against viruses representative of two of the three genera of the Flaviviridae family, i.e. Flaviviruses (YFV) and Pestiviruses (BVDV), as Hepaciviruses can hardly be used in routine cell-based assays. Title compounds were also tested against representatives of other virus families. Among ssRNA ${ }^{+}$were HIV-1 (Retroviridae), CVB-2 and Polio-1 (Picornaviridae); among ssRNA- were RSV (Paramyxoviridae) and VSV (Rhabdoviridae); among double-stranded RNA (dsRNA) viruses were Reo-1 (Reoviridae). Two representatives of DNA virus families were also included: HSV-1 (Herpesviridae) and VV (Poxviridae).

Compounds exhibited different cytotoxicity, in particular, oxindoles $4, \mathbf{5}, \mathbf{7}, \mathbf{8}, \mathbf{9}, \mathbf{1 0}, \mathbf{1 1}, \mathbf{1 2}, \mathbf{1 3}, \mathbf{5 8}$ as well as thiazole/triazole $\mathbf{7 3}$ and $\mathbf{7 5}$ turned out to be the most cytotoxic for MT-4 cell lines (table 3).

Table 3

Bioactivity synthesized compounds against MT-4, MDBK, BHK-21, Vero-76, HIV-1, BVDV, YFV, CVB-2, Sb-1, VSV, VV, HSV-1 (in vitro)

\begin{tabular}{|c|c|c|c|c|c|c|c|c|c|c|c|c|}
\hline \multirow[t]{2}{*}{ Comps } & MT-4 & MDBK & BHK-21 & Vero-76 & HIV-1 & BVDV & YFV & CVB-2 & Sb-1 & VSV & VV & HSV-1 \\
\hline & \multicolumn{4}{|c|}{$\mathrm{CC50}[\mu \mathrm{M}]$} & \multicolumn{8}{|c|}{ EC50 $[\mu \mathrm{M}]$} \\
\hline 1 & $>100$ & $>100$ & $>100$ & $>100$ & $>100$ & $>100$ & $>100$ & $>100$ & $>100$ & $>100$ & $>100$ & $>100$ \\
\hline 2 & $>100$ & $>100$ & $>100$ & $>100$ & $>100$ & $>100$ & $>100$ & $>100$ & $>100$ & $>100$ & $>100$ & $>100$ \\
\hline 3 & $>100$ & $>100$ & $>100$ & $>100$ & $>100$ & $>100$ & $>100$ & $>100$ & $>100$ & $>100$ & $>100$ & $>100$ \\
\hline 4 & 47 & $>100$ & $>100$ & $>100$ & $>47$ & $>100$ & $>100$ & $>100$ & $>100$ & $>100$ & $>100$ & $>100$ \\
\hline 5 & 55 & $>100$ & $>100$ & $>100$ & $>55$ & $>100$ & $>100$ & $>100$ & $>100$ & $>100$ & $>100$ & $>100$ \\
\hline 6 & $>100$ & 93 & $>100$ & $>100$ & $>100$ & $>93$ & $>100$ & $>100$ & $>100$ & $>100$ & $>100$ & $>100$ \\
\hline 7 & 59 & $>100$ & $>100$ & $>100$ & $>59$ & $>100$ & $>100$ & $>100$ & $>100$ & $>100$ & $>100$ & $>100$ \\
\hline 8 & 49 & $>100$ & $>100$ & $>100$ & $>49$ & $>100$ & $>100$ & $>100$ & $>100$ & $>100$ & $>100$ & $>100$ \\
\hline 9 & 33 & $>100$ & $>100$ & $>100$ & $>33$ & $>100$ & $>100$ & $>100$ & $>100$ & $>100$ & $>100$ & $>100$ \\
\hline 10 & 29 & $>100$ & $>100$ & $>100$ & $>29$ & $>100$ & $>100$ & $>100$ & $>100$ & $>100$ & $>100$ & $>100$ \\
\hline 11 & 17 & $>100$ & $>100$ & $>100$ & $>17$ & $>100$ & $>100$ & $>100$ & $>100$ & $>100$ & $>100$ & $>100$ \\
\hline 12 & 19 & $>100$ & $>100$ & $>80$ & $>19$ & 85 & $>100$ & $>80$ & $>80$ & $>80$ & $>80$ & $>100$ \\
\hline 13 & 45 & $>18$ & $>19$ & $>40$ & $>45$ & $>18$ & $>19$ & $>40$ & $>40$ & $>40$ & $>40$ & $>19$ \\
\hline 14 & $>100$ & $>100$ & $>100$ & $>100$ & $>100$ & $>100$ & $>100$ & $>100$ & $>100$ & $>100$ & $>100$ & $>100$ \\
\hline 15 & $>100$ & $>100$ & $>100$ & $>100$ & $>100$ & $>100$ & $>100$ & $>100$ & $>100$ & $>100$ & $>100$ & $>100$ \\
\hline 16 & $>100$ & $>100$ & $>100$ & $>100$ & $>100$ & $>100$ & $>100$ & $>100$ & $>100$ & $>100$ & $>100$ & $>100$ \\
\hline 17 & $>100$ & $>100$ & $>100$ & $>100$ & $>100$ & $>100$ & $>100$ & $>100$ & $>100$ & $>100$ & $>100$ & $>100$ \\
\hline 18 & $>100$ & $>100$ & $>100$ & $>100$ & $>100$ & $>100$ & $>100$ & $>100$ & $>100$ & $>100$ & $>100$ & $>100$ \\
\hline 52 & $>100$ & $>100$ & $>100$ & $>100$ & $>100$ & 6.6 & $>100$ & $>100$ & $>90$ & $>90$ & $>100$ & $>100$ \\
\hline 54 & $>100$ & $>100$ & $>100$ & $>100$ & $>100$ & $>100$ & $>100$ & $>100$ & $>100$ & $>100$ & $>100$ & $>100$ \\
\hline 56 & $>100$ & $>100$ & $>100$ & $>100$ & $>100$ & $>94$ & $>100$ & $>100$ & $>100$ & $>100$ & $>100$ & $>100$ \\
\hline 55 & $>100$ & $>100$ & $>100$ & $>80$ & $>100$ & $>100$ & $>100$ & $>100$ & $>100$ & $>100$ & $>100$ & $>100$ \\
\hline 57 & $>100$ & $>100$ & $>100$ & $>100$ & $>100$ & $>100$ & $>100$ & $>80$ & $>80$ & $>80$ & $>80$ & $>100$ \\
\hline 58 & 51 & $>100$ & $>100$ & $>100$ & $>51$ & 22 & $>100$ & $>100$ & $>100$ & $>100$ & $>100$ & $>100$ \\
\hline
\end{tabular}




\begin{tabular}{|c|c|c|c|c|c|c|c|c|c|c|c|c|}
\hline $\mathbf{5 9}$ & $>100$ & $>100$ & $>100$ & $>100$ & $>100$ & $>100$ & $>100$ & $>100$ & $>100$ & $>100$ & $>100$ & $>100$ \\
\hline $\mathbf{6 1}$ & $>100$ & $>100$ & $>100$ & $>90$ & $>100$ & $>100$ & $>100$ & $>90$ & $>90$ & $>90$ & $>90$ & $>100$ \\
\hline $\mathbf{6 2}$ & $>100$ & $>100$ & $>100$ & $>100$ & $>100$ & $>100$ & $>100$ & $>100$ & $>100$ & $>100$ & $>100$ & $>100$ \\
\hline $\mathbf{6 3}$ & $>100$ & $>100$ & $>100$ & $>100$ & $>100$ & $>100$ & $>100$ & $>100$ & $>100$ & $>100$ & $>100$ & $>100$ \\
\hline $\mathbf{7 0}$ & $>100$ & $>100$ & $>100$ & $>100$ & $>100$ & $>100$ & $>100$ & $>100$ & $>100$ & $>100$ & $>100$ & $>100$ \\
\hline $\mathbf{7 1}$ & $>100$ & $>100$ & $>100$ & $>100$ & $>100$ & $>100$ & $>100$ & $>100$ & $>100$ & $>100$ & $>100$ & $>100$ \\
\hline $\mathbf{7 2}$ & $>100$ & $>100$ & $>100$ & $>100$ & $>100$ & $>100$ & $>100$ & $>100$ & $>100$ & $>100$ & $>100$ & $>100$ \\
\hline $\mathbf{7 3}$ & $\leq 3.7$ & 16 & $>100$ & 18 & $>100$ & $>16$ & $>100$ & $>18$ & $>18$ & $>18$ & $>18$ & $>100$ \\
\hline $\mathbf{7 4}$ & $>100$ & $>100$ & $>100$ & $>100$ & $>100$ & $>100$ & $>100$ & $>100$ & $>100$ & $>100$ & $>100$ & $>100$ \\
\hline $\mathbf{7 5}$ & 16 & 55 & $>100$ & 90 & $>16$ & $>55$ & $>100$ & $>90$ & $>90$ & $>90$ & $>90$ & $>100$ \\
\hline $\mathbf{7 7}$ & $>100$ & $>100$ & $>100$ & $>100$ & $>100$ & $>87$ & $>100$ & $>100$ & $>100$ & $>100$ & $>100$ & $>100$ \\
\hline $\mathbf{7 8}$ & $>100$ & $>100$ & $>100$ & $>100$ & $>100$ & $>100$ & $>100$ & $>100$ & $>100$ & $>100$ & $>100$ & $>100$ \\
\hline $\mathbf{7 9}$ & $>100$ & $>100$ & $>100$ & $>100$ & $>100$ & $>100$ & $>100$ & $>100$ & $>100$ & $>100$ & $>100$ & $>100$ \\
\hline $\mathbf{8 0}$ & $>100$ & $>100$ & $>100$ & $>100$ & $>100$ & $>100$ & $>100$ & $>100$ & $>100$ & $>100$ & $>100$ & $>100$ \\
\hline $\mathbf{8 1}$ & $>100$ & $>100$ & $>100$ & $>100$ & $>100$ & $>100$ & $>100$ & $>100$ & $>100$ & $>100$ & $>100$ & $>100$ \\
\hline
\end{tabular}

It is worth noting that compounds $\mathbf{1 1}, \mathbf{1 2}, \mathbf{7 3}$, and $\mathbf{7 5}$ are more toxic than reference compound Efavirenz.

As far as the antiviral activity is concerned, none of the title compounds exhibited any activity against Reo-1, Sb-1, VSV, RSV, YFV and VV viruses.

The results obtained against Bovine Viral Diarrhoea Virus (BVDV) showed that nine compounds (six from oxindol's seria $\mathbf{6 , 1 2}, \mathbf{1 3}, \mathbf{5 2}, \mathbf{5 6}, \mathbf{5 8}$ and three 73, 75, 77 of triazole homologues) resulted moderate active. Among all of them, the most potent compound was $\mathbf{5 2}$, with $\mathrm{EC}_{50}$ of $6.6 \mu \mathrm{M}$.

Studies of effect of synthesized compounds against Coxsakie Virus (CVB-2) revealed that only two compounds, 13 and 73 exhibit moderate activity $\left(\mathrm{EC}_{50}>40\right.$ and $>18 \mu \mathrm{M}$, respectively).

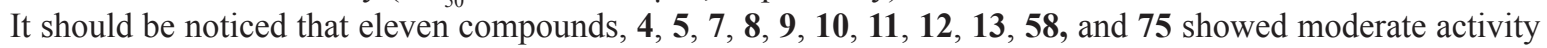
against HIV-1 $\left(\mathrm{EC}_{50}>16-\mathrm{m}>59 \mu \mathrm{M}\right)$.

\section{Conclusions}

In the light of the above-mentioned results, we conclude that synthesized compounds in general not so active as antiviral agent. But some of them showed, good activity against viruses containing a single-stranded positive-sense RNA genome $\left(\right.$ ssRNA $^{+}$). In particular, in cell-based assays the compounds $\mathbf{1 1}, \mathbf{1 2}, \mathbf{5 2}, \mathbf{5 7}, \mathbf{7 3}$, and 75 results the most potent against MT4 cells, BVDV, and HIV-1, respectively.

\section{Acknowledgements}

The authors gratefully acknowledge to professor Paola La Colla from University of Cagliari, Italy for providing data an antiviral activity studied compounds.

\section{Experimental methods}

Solvents and commercially available reagents $(1 H$-indole-2,3-dione 25, 1-methyl-1H-indole-2,3-dione 26, 1 -ethyl-1Hindole-2,3-dione 27, 1-benzyl-1H-indole-2,3-dione 46) were purchased from Aldrich and used without additional purification. 1-Alkylindoline-2,3-diones 28-31, 33-42 were obtained by a known method [32,33]. Melting points were determined on a Boëtius melting point apparatus (PHMK, VEB Wägetechnik Rapido, Radebeul, Germany) and are uncorrected. ${ }^{1} \mathrm{H}$ - NMR spectra were acquired on a Bruker Avance III 400 spectrometer operating at $400.13 \mathrm{MHz}$ for ${ }^{1} \mathrm{H}$. Chemical shifts $\delta$ are given in ppm referring to the signal center using the solvent peaks for reference: DMSO- $\mathrm{d}_{6} 2.50 \mathrm{ppm}$. IR spectra were acquired on apparatus "Perkin-Elmer Spectrum 100 FTIR". Electron ionisation mass-spectra were recorded on a VG-250 spectrometer (VG Labs., Tritech England) with ionisation energy maintained at $70 \mathrm{eV}$.

\section{General procedure for synthesis of oxindoles 1-18}

A mixture of indoline-2,3-dione $(10 \mathrm{mmol})$, ketone $(10 \mathrm{mmol})$, and $\mathrm{Et}_{2} \mathrm{NH}(0.73 \mathrm{~g}, 10 \mathrm{mmol})$ in $25 \%$ aq. ethylene glycol $(20 \mathrm{ml})$ was stirred for 6-8 hours at room temperature (TLC control). The precipitate was filtered off, and washed with $25 \%$ aq. ethylene glycol $(3 \times 10 \mathrm{ml})$. The crystalline product was used for further synthesis without purification. For analytical purposes, a sample was recrystallized from a suitable solvent.

3-Hydroxy-3-(2-oxopropyl)indolin-2-one 1. M.p. 168-169 ${ }^{\circ} \mathrm{C}$, Ref. [38] 160-165 ${ }^{\circ} \mathrm{C}$.

3-Hydroxy-1-methyl-3-(2-oxopropyl)indolin-2-one 2. M.p. 147-148 ${ }^{\circ}$, Ref. [38] 140-145 ${ }^{\circ} \mathrm{C}$.

3-(2-(2,4-Dichlorophenyl)-2-oxoethyl)-3-hydroxy-1-methylindolin-2-one 9. Yield 87\%, M.p. 162-164º C. Ref. [27] M.p. $161-164^{\circ} \mathrm{C}$. 
3-(2-(2,4-Dichlorophenyl)-2-oxoethyl)-1-ethyl-3-hydroxyindolin-2-one 10. Yield 78 \%, M.p. 137-138 C. Ref. [27] M.p. $135-138^{\circ} \mathrm{C}$.

1-Butyl-3-(2-(2,4-dichlorophenyl)-2-oxoethyl)-3-hydroxyindolin-2-one 11. Yield 95 \%, oil. Cal. C 61.24; H 4.88; N, 3.57. $\mathrm{C}_{20} \mathrm{H}_{19} \mathrm{Cl}_{2} \mathrm{NO}_{3}$. Find. C 61.29; $\mathrm{H} 4.60 ; \mathrm{N}, 3.58$. Ref. [27] Oil.

3-(2-(2,4-Dichlorophenyl)-2-oxoethyl)-1-hexyl-3-hydroxyindolin-2-one 12. Yield 98 \%, oil. Cal. C 62.86; H 5.52; N 3.33. $\mathrm{C}_{22} \mathrm{H}_{23} \mathrm{Cl}_{2} \mathrm{NO}_{3}$. Find. C 62.77; $\mathrm{H}$ 5.52; N 3.26. Ref. [27] Oil.

1-Decyl-3-(2-(2,4-dichlorophenyl)-2-oxoethyl)-3-hydroxyindolin-2-one 13. Yield 99 \%, oil. Cal. C 65.54; H 6.56; N 2.94. $\mathrm{C}_{26} \mathrm{H}_{31} \mathrm{Cl}_{2} \mathrm{NO}_{3}$. Find. C 65.39; H 6.56; N 2.88. Ref. [27] Oil.

2-((1S,3S)-3-(2-(3-Hydroxy-2-oxoindolin-3-yl)acetyl)-2,2-dimethylcyclobutyl)-acetamide 14. Yield 68 \%, M.p. 206-207 ${ }^{\circ}$ C. Ref. [28] M.p. $205-207^{\circ} \mathrm{C}$.

2-((1S,3S)-3-(2-(3-Hydroxy-2-oxoindolin-3-yl)acetyl)-2,2-dimethylcyclobutyl)-acetonitrile 15. Yield $81 \%$, M.p. $163-164^{\circ} \mathrm{C}$. Ref. [28] M.p. $163-164^{\circ} \mathrm{C}$.

Methyl 2-((1S,3S)-3-(2-(3-hydroxy-2-oxoindolin-3-yl)acetyl)-2,2-dimethyl-cyclobutyl)acetate 16. Yield 88 \%, M.p. $76-77^{\circ} \mathrm{C}$. Ref. [28] M.p. $76^{\circ} \mathrm{C}$.

Methyl 2-((1S,3S)-3-(2-(1-ethyl-3-hydroxy-2-oxoindolin-3-yl)acetyl)-2,2-dimethylcyclobutyl)acetate 17. Yield 55 $\%$, M.p. $162-163^{\circ} \mathrm{C}$. Ref. [28] M.p. $162-164^{\circ} \mathrm{C}$.

Methyl 2-((1S,3S)-3-(2-(1-benzyl-3-hydroxy-2-oxoindolin-3-yl)acetyl)-2,2-dimethylcyclobutyl)acetate 18. Yield $79 \%$, M.p. $152-153^{\circ} \mathrm{C}$. Ref. [28] M.p. $152-153^{\circ} \mathrm{C}$.

\section{General procedure for synthesis of thiosemicarbazones 43-53, 70-72}

The ketones $(1 \mathrm{mmol})$ in EtOH $(10 \mathrm{ml})$ and thiosemicarbazide $(1 \mathrm{mmol})$ in EtOH $(10 \mathrm{ml})$ were mixed at $50^{\circ} \mathrm{C}$. Three drops of $30 \% \mathrm{HCl}$ were added to the mixed solution following by reflux for 1-6 hours (TLC control). The mixture was cooled and precipitate was filtered and recrystallized using an appropriate solvent.

\section{General procedure for heterocyclization of thiosemicarbazones into 1,3,4-thiadiazolines 73-75}

After refluxing during 3-6 hours of thiosemicarbazones 70-72 $(10 \mathrm{mmol})$ in $\mathrm{Ac}_{2} \mathrm{O}(25 \mathrm{ml})$ the solution was cooled and after addition of $\mathrm{H}_{2} \mathrm{O}(5 \mathrm{ml})$ kept overnight at room temperature. The solid was filtered off, washed with cold $\mathrm{H}_{2} \mathrm{O}$, dried over $\mathrm{P}_{2} \mathrm{O}_{5}$ and recrystallized from appropriate solvent.

N-\{5-[(1H-1,2,4-Triazol-1-yl)methyl)-4-acetyl-5-(2,4-dichlorophenyl]-4,5-dihydro-1,3,4-thiadiazol-2-yl\} acetamide 73. MS, $\mathrm{m} / \mathrm{z}$ (relative intensity \%): [M] 277 (100), 208 (23), 188 (61), 181 (15), 163 (11), 155 (10), 140 (23), 139 916), 138 (56), 137 (38), 132 (8), 123 (7), 114 (8), 113 (9), 111 (17), 102 (12), 90 (8), 86 (10), 81 (8), 76 (8), 75 (13), 70 (10), 60 (89), 32 (25).

N-\{5-[(1H-1,2,4-Triazol-1-yl)methyl]-4-acetyl-5-p-tolyl-4,5-dihydro-1,3,4-thiadiazol-2-yl\}acetamide 74. MS, m/z (relative intensity \%): [M] 269 (16), 259(27), 258 (92), 203 (15), 189 (14), 188 (27), 162 (8), 161 (22), 147 (12), 145 (10), 143 (10), 135 (9), 119 (21), 118 (100), 117 (34), 116 (18), 103 (10), 92 (8), 91 (37), 90 (16), 89 (17), 86 (13), 77 (10), 76 (9), 71 (7), 69 (10), 65 (19), 64 (11), 63 (21), 62 (14), 61 (17), 60 (51), 59 (12), 54 (16), 53 (11), 51 (22), 50 (14), 45 (10), 42 (10), 41 (13).

N-\{5-[(1H-1,2,4-Triazol-1-yl)methyl]-4-acetyl-5-phenyl-4,5-dihydro-1,3,4-thiadiazol-2-yl\}acetamide 75. MS, $\mathrm{m} / \mathrm{z}$ (relative intensity \%): [M]+315 (9), 314 (19), 313 (47), 312 (28), 311 (66), 279 (8), 278 (54), 277 (12), 276 (100), 275 (12), 224 (15), 222(21), 197 (11), 195 (22), 194 (8), 174 (9), 173 (11), 172 (20), 171 (19), 136 (9), 60 (32), 59 (12).

\section{General procedure for the preparation of 4-aryl-5-(1H-1,2,4-triazol-1-yl)-1,3-thiazol-2-amines 77-81}

The bromination of ketones 64, 65, and 67-69 were realized with $\mathrm{Br}_{2}$ in mixture $\mathrm{HBr} / \mathrm{AcOH}$ at $10^{\circ} \mathrm{C}$. The crude product 76 was used without purification in the next step. Mixture of bromide $(0.01 \mathrm{~mol}) \mathbf{7 6}$ and thiourea $(0.01 \mathrm{~mol})$ in acetone $(20 \mathrm{ml})$ was stirred at room temperature for 1 hour and after removal of the solvent, the resulting solid was refluxed in ethanol ( $50 \mathrm{ml})$ for additional 2 hours. After evaporation of the EtOH, $5 \%$ water solution of $\mathrm{NaHCO}_{3}(50 \mathrm{ml})$ was added and mixture was refluxed 8 hours. The solid was collected by filtration, dried and recrystallized from ethanol.

\section{Biological Assays}

Compounds were dissolved in DMSO at $100 \mathrm{mM}$ and then diluted in culture medium.

\section{Cells and Viruses.}

Cell lines were purchased from American Type Culture Collection (ATCC). The absence of mycoplasma contamination was checked periodically by the Hoechst staining method. Cell lines supporting the multiplication of RNA viruses were the following: CD4 ${ }^{+}$human T-cells containing an integrated HTLV-1 genome (MT-4); Madin Darby Bovine Kidney (MDBK); Baby Hamster Kidney (BHK-21) and Monkey Kidney (Vero 76) cells. 


\section{Cytotoxicity Assays}

For cytotoxicity tests, run in parallel with antiviral assays, MDBK and BHK cells were re-suspended in 96 multi-well plates at an initial density of $6 \times 10^{5}$ and $1 \times 10^{6}$ cells $/ \mathrm{mL}$, respectively, in maintenance medium, without or with serial dilutions of test compounds. Cell viability was determined after $48-96$ hrs at $37{ }^{\circ} \mathrm{C}$ in a humidified $\mathrm{CO}_{2}(5 \%)$ atmosphere by the 3-(4,5-dimethylthiazol-2-yl)-2,5-diphenyl-tetrazolium bromide (MTT) method [39].

Vero 76 cells were re-suspended in 24 multi-well plates at an initial density of $4 \times 10^{5}$ cells $/ \mathrm{mL}$. The cell number of Vero 76 monolayers was determined by staining with the crystal violet dye.

For cytotoxicity evaluations, exponentially growing cells derived from human haematological tumors $\left[\mathrm{CD} 4^{+}\right.$human T-cells containing an integrated HTLV-1 genome (MT-4)] were seeded at an initial density of $1 \times 10^{5} \mathrm{cells} / \mathrm{mL}$ in 96 well plates in RPMI-1640 medium supplemented with $10 \%$ fetal calf serum (FCS), 100 units $/ \mathrm{mL}$ penicillin G and $100 \mu \mathrm{g} / \mathrm{mL}$ streptomycin. Cell cultures were then incubated at $37{ }^{\circ} \mathrm{C}$ in a humidified, $5 \% \mathrm{CO}$ atmosphere in the absence or presence of serial dilutions of test compounds. Cell viability was determined after $96 \mathrm{hrs}$ at $37^{\circ} \mathrm{C}$ by the MTT method.

\section{Antiviral assay}

Activity of compounds against Human Immunodeficiency Virus type-1 (HIV-1) was based on inhibition of virus-induced cytopathogenicity in MT-4 cells acutely infected with a multiplicity of infection (m.o.i.) of 0.01 . Briefly, $50 \mu \mathrm{L}$ of RPMI containing $1 \times 10^{4}$ MT-4 were added to each well of flat-bottom microtitre trays containing $50 \mu \mathrm{L}$ of RPMI, without or with serial dilutions of test compounds. Then, $20 \mu \mathrm{L}$ of an HIV-1 suspension containing $100 \mathrm{CCID}_{50}$ were added. After a 4-day incubation, cell viability was determined by the MTT method.

Activity of compounds against Yellow Fever Virus (YFV) and Reo Virus type-1 (Reo-1) was based on inhibition of virus-induced cytopathogenicity in acutely infected BHK-21 cells. Activities against Bovine Viral Diarrhoea Virus (BVDV), in infected MDBK cells, were also based on inhibition of virus-induced cytopathogenicity.

BHK and MDBK cells were seeded in 96-well plates at a density of $5 \times 10^{4}$ and $3 \times 10^{4}$ cells/well, respectively, and were allowed to form confluent monolayers by incubating overnight in growth medium at $37^{\circ} \mathrm{C}$ in a humidified $\mathrm{CO}_{2}(5 \%)$ atmosphere. Cell monolayers were then infected with $50 \mu \mathrm{L}$ of a proper virus dilution (in serum-free medium) to give an m.o.i $=0.01 .1 \mathrm{hr}$ later, $50 \mu \mathrm{L}$ of MEM Earle's medium, supplemented with inactivated foetal calf serum (FCS), $1 \%$ final concentration, without or with serial dilutions of test compounds, were added. After 3-4 days incubation at $37^{\circ} \mathrm{C}$, cell viability was determined by the MTT method.

Activity of compounds against Coxsackie Virus, B-2 strain (CVB-2), Polio Virus type-1 (Polio-1), Sabin strain, and Vesicular Stomatitis Virus (VSV), Vaccinia Virus (VV) and Herpes Virus 1 (HSV-1) and against Respiratory Syncytial Virus (RSV), A-2 strain, in infected Vero 76 cells, was determined by plaque reduction assays in Vero 76 cell monolayers. To this end, Vero 76 cells were seeded in 24-well plates at a density of $2 \times 10^{5}$ cells/well and were allowed to form confluent monolayers by incubating overnight in growth medium at $37{ }^{\circ} \mathrm{C}$ in a humidified $\mathrm{CO}_{2}(5 \%)$ atmosphere. Then, monolayers were infected with $250 \mu \mathrm{L}$ of proper virus dilutions to give 50-100 PFU/well. Following removal of unadsorbed virus, $500 \mu \mathrm{L}$ of Dulbecco's modified Eagle's medium supplemented with 1\% inactivated FCS and 0.75\% methyl cellulose, without or with serial dilutions of test compounds, were added. Cultures were incubated at $37{ }^{\circ} \mathrm{C}$ for 2 (Sb-1 and VSV), 3 (CVB-2, VV and HSV-1) or 5 days (RSV) and then fixed with PBS containing 50\% ethanol and 0.8\% crystal violet, washed and air-dried. Plaques were then counted. $50 \%$ effective concentrations $\left(\mathrm{EC}_{50}\right)$ were calculated by linear regression technique.

\section{References}

[1]. Jiang, X.; Cao, Y.;.Wang, Y; Liu, L.; Shen, F.; Wang, R. J. Am. Chem. Soc., 2010, 132, 15328-15333.

[2]. Satyamaheshwar, P. Current Bioactive Compounds. 2009, 5, 20-38.

[3]. Lawrence, H. R.; Pireddu, R,; Chen, L.; Luo, Y.; Sung, S.-S.; Szymanski, A. M.; Yip, M. L. R.; Guida, W. C.; Sebti, S. M.; Wu, J.; Lawrence, N. J. J. Med. Chem. 2008, 51, 4948-4956.

[4]. Fensome, A.; Adams, W. R.; Adams, A. L.; Berrodin, T. J.; Cohen, J.; Huselton, C.; Illenberger, A.; Kern, J. C.; Hudak, V. A.; Marella, M. A.; Melenski, E. G.; McComas, C. C.; Mugford, C. A.; Slayden, O. D.; Yudt, M.; Zhang, Z.; Zhang, P.; Zhu, Y.; Winneker, R. C.; Wrobel J. E. J. Med. Chem. 2008, 51, 1861-1873.

[5]. Macpherson, L.J.; Dubin, A. E.; Evans, M.J.; Marr, F.; Schultz, P. G.; Cravatt, B. F.; Patapoutian, A. Nature. 2007, 445, 541-545.

[6]. Deiters, A.; Pettersson, M.; Martin, S. F. J. Org. Chem. 2006, 71, 6547-6561.

[7]. Emura, T.; Esaki, T.; Tachibana, K.; Shimizu, M. J. Org. Chem. 2006, 71, 8559-8564.

[8]. Kogure, N.; Ishii, N.; Kitajima, M.; Wongseripipatana, S.; Takayama, H. Org. Lett. 2006, 8, 3085-3088.

[9]. Natarajan, A.; Guo, Y.; Harbinski, F.; Fan, Y.-H.; Chen, H.; Luus, L.; Diercks, J.; Aktas, H.; Chorev, M.; Halperin, J. A. J. Med. Chem. 2004, 47, 4979-4982.

[10]. Macaev, F. Synthesis of spiroindolin-2-ones from 1H-indole-2,3-dione. In INTERBIOSCREEN MONOGRAPH SERIES "Selected methods for synthesis and modification of heterocycles". Vol. 3. The chemistry of synthetic indole systems. IBS press: Moskow, 2004; pp 75-102. 
[11]. Geronikaki, A.; Babaev, E.; Dearden, J.; Dehaen, W.; Filimonov, D.; Galaeva, I.; Kraineva, V.; Lagunin, A.; Macaev, F.; Molodavkin, G.; Poroikov, V.; Pogrebnoi, S.; Saloutin, V.; Stepanchikova, A.; Stingaci, E.; Tkach, N.; Vlad, L.; Voronina, T. Bioorganic \& Medicinal Chemistry. 2004, 12, 6559-6568.

[12]. Takayama, H.; Fujiwara, R.; Kasai, Y.; Kitajima, M.; Aimi, N. Org. Lett. 2003, 5, 2967-2970.

[13]. Woodard, C. L.; Li, Z.; Kathcart, A. K.; Terrell, J.; Gerena, L.; Lopez-Sanchez, M.; Kyle, D. E.; Bhattacharjee, A. K.; Nichols, D. A.; Ellis, W.; Prigge, S. T.; Geyer, J. A.; Waters, N. C. J. Med. Chem. 2003, 46, 3877-3882.

[14]. Bramson, H. N.; Corona, J.; Davis, S. T.; Dickerson, S. H.; Edelstein, M.; Frye, S. V.; Gampe, R. T.; Harris, Jr. P. A.; Hassell, A.; Holmes, W. D.; Hunter, R. N.; Lackey, K. E.; Lovejoy, B.; Luzzio, M. J.; Montana, V.; Rocque, W. J.; Rusnak, D.; Shewchuk, L.; Veal, J. M.; Walker, D. H.; Kuyper, L. F. J. Med. Chem., 2001, 44, 4339-4358.

[15]. Tokunaga, T.; Hume, W. E.; Umezome, T.; Okazaki, K.; Ueki, Y.; Kumagai, K.; Hourai, S.; Nagamine, J.; Seki, H.; Taiji, M.; Noguchi, H.; Nagata, R. J. Med. Chem. 2001, 44, 4641-4649.

[16]. Cravotto, G.; Giovenzana, G. B.; Pilati, T.; Sisti, M.; Palmisano, G. J. Org. Chem. 2001, 66, 8447-8453.

[17]. Carletti, I.; Banaigs, B.; Amade, P. J. Nat. Prod. 2000, 63, 981-983.

[18]. El-Gendy, A. A.; Ahmedy, A. M. Archives of Pharmacia Research. 2000, 23, 310-314.

[19]. Robinson, R. P.; Reiter, L. A.; Barth, W. E.; Campeta, A. M.; Cooper, K.; Cronin, B. J.; Destito, R.; Donahue, K. M.; Falkner, F. C.; Fiese, E. F.; Johnson, D. L.; Kuperman, A. V.; Liston, T. E.; Malloy, D.; Martin, J. J.; Mitchell, D. Y.; Rusek, F. W.; Shamblin, S. L.; Wright, C. F. J. Med. Chem. 1996, 39, 10-18.

[20]. Itakura, K.; Uchida, K.; Kawakishi, S. Chem. Res. Toxicol. 1994, 7, 185-190.

[21]. Takayama, H.; Kitajima, M.; Ogata, K.; Sakai, S. J. Org. Chem. 1992, 57, 4583-4584.

[22]. Ling, S.; Xin, Z.; Qing, Z.; Jian-Bing, L.; Zhong, J.; Jian-Xin, F. Synthetic communications. 2007, 37, $199-207$.

[23]. Neil John Press, Roger John Taylor. US Patent, 0053982 A1, 2004.

[24]. Neil John Press, Roger John Taylor. WO Patent, 02/42298 A1, 2002.

[25]. Carosati, E.; Mannhold, R.; Wahl, P.; Hansen, J. B.; Fremming, T.; Zamora, I.; Cianchetta, G.; Baronir, M. J. Med. Chem. 2007, 50, 2117-2126.

[26]. Macaev, F.; Sucman, N.; Shepeli, F.; Zveaghintseva, M.; Pogrebnoi, V. Symmetry. 2011, 3, 165-170.

[27]. Macaev, F.Z.; Radul, O.M.; Sterbet, I.N.; Pogrebnoi, S.I.; Sucman, N.S.; Malinovskii, S.T.; Barba, A.N.; Gdaniec, M. Chem. Heterocyclic Comps. 2007, 3, 374-383.

[28]. Macaev, F.Z.; Radul, O.M.; Gudima, A.P. Russ. Chem. Bull. 2008, 57, 1571-1574.

[29]. Makaev, F. Z.; Radul, O. M.; Gdanets, M.; Malinovskii, S. T.; Gudima, A. P. Russ. J. Struct. Chem. 2006, 47, 796-799. (Engl. Transl.).

[30]. Rekhter, M.A.; Rekhter, B.A.; Yazlovetskii, I.G.; Panasenko, A.A.; Macaev, F.Z. Chem. Heterocyclic Comps. 1998, 34, 275-277.

[31]. Rekhter, M.A.; Macaev, F.Z.; Babilev, F.V.; Grushetskaea, G.N.; Rudakov, S.V. Chem. Heterocyclic Comps. 1996, 32, 418-422.

[32]. Radul, O. M.; Zhungietu, G.I.; Rekhter, M.A.; Bukhanyuk, S.M. Chem. Heterocyclic Comps. 1983, $3,353$.

[33]. Zhungietu, G.I.; Rekhter, M.A. Isatin and its derivatives. Ştiinţa: Chişinău, 1977; pp 36-39.

[34]. Weiss, M.M.; Weiss, P.D.; Mathisen, G.; Guze, P. Clin. Infect. Dis. 2004, 39, 1668-1673.

[35]. Radul, O. M.; Malinovskii, S. T.; Luboradskii, R.; Makaev, F. Z. J. Structural Chem. 2005, 46, 753-758.

[36]. Pogrebnoi, S.I. Ph.D. Thesis, Institute of chemistry of ASM, Chişinău, 2006.

[37]. Fjita, T.; Kitazawa, Y.; Akita, T.; Tani, I. US Patent, 45770321989.

[38]. Malkov, A.V.; Kabeshov, M.A.; Bella, M.; Kysika, O.; Malyshev D.A.; Pluhackova, K.; Kocovsky, P. Org. Lett., 2007, 9, 5473-5476.

[39]. Pauwels, R.; Balzarini, J.; Baba, M.; Snoeck, R.; Schols, D.; Herdewijn, P.; Desmyster, J.; De Clercq, E.J. Virol. Methods. 1998, 20, 309. 